\title{
Stress reversal recorded in calcite vein cuttings from the Nankai accretionary prism, southwest Japan
}

\author{
${\text { Toru Takeshita }{ }^{1 *}, \text { Asuka Yamaguchi }^{2} \text { and Norio Shigematsu }}^{3}$
}

\begin{abstract}
The Nankai Trough subduction zone in southwest Japan is a typical convergent margin where the Philippine Sea plate subducts in the northwest direction beneath the Eurasian plate, and devastating earthquakes have repeatedly occurred in this region in the past. In order to investigate the evolution of the stress state in the subduction zone, we analyzed deformation microstructures and the preferred orientation of calcite grains in two cuttings of calcite veins from Hole C0002F that was drilled through the inner wedge of the Nankai accretionary prism during the Integrated Ocean Discovery Program (IODP) Expedition 338 in 2012. For both samples collected at depths of 1,085.5 and 1,885.5 meters below the sea floor (mbsf), the c-axes of calcite grains are preferentially oriented perpendicular to the vein wall, which is indicative of competitive growth of calcite during the vein opening caused by a vein normal extension. Also, mechanical e-twins were developed in both samples, and these are inferred to have been developed under the same stress field as that responsible for the formation of calcite veins based on the paleostress analyses in grains with e-twins. For the calcite vein retrieved at the depth of 1,885.5 mbsf, kink bands were also developed by the compression in the direction perpendicular to the vein wall, which is indicative of stress reversal after the formation of mechanical e-twins. Although we could not reach a definite conclusion for the cause of the stress reversal, it could have occurred during either fold development or seismic cycles in the Nankai accretionary prism.
\end{abstract}

Keywords: IODP expedition 338; Nankai accretionary prism; Calcite vein; Stress reversal; Paleostress analyses

\section{Background}

Subduction zones, which are areas where an oceanic plate subducts underneath a continental or oceanic plate, are well-known places for the generation of large-scale earthquakes and magma production leading to arc volcanism. The Nankai Trough is formed by the subduction of the Philippine Sea plate in the northwest direction beneath the Eurasian plate at a rate of 4 to $6 \mathrm{~cm} / \mathrm{y}$ (Seno et al. 1993; Miyazaki and Heki, 2001). Additionally, sediments of the Shikoku Basin, which opened as a back-arc basin behind the Izu-Bonin arc-trench system between 26 to 15 Ma (Chamot-Rooke et al. 1987), are actively accreting at the plate boundary and forming a modern accretionary prism. Devastating earthquakes have recently repeatedly occurred at three major districts called the Tokai,

\footnotetext{
* Correspondence: torutake@mail.sci.hokudai.ac.jp

${ }^{1}$ Department of Natural History Sciences, Graduate School of Sciences, Hokkaido University, Sapporo 060-0810, Japan

Full list of author information is available at the end of the article
}

Tonankai, and Nankai districts from east to west along the subduction zone beneath the Nankai Trough (e.g., Ando, 1975; Park and Kodaira, 2012). The Nankai Trough Seismogenic Zone Experiments (NanTroSEIZE) project of the Integrated Ocean Drilling Program, now called the International Ocean Discovery Program (IODP), has been designed so that the processes and mechanisms of subduction zone earthquakes and tsunamis can be clarified through multidisciplinary approaches including geophysical logging, in situ geochemical observations, and sedimentological and structural observations of retrieved cores and cuttings (e.g., Tobin and Kinoshita, 2006; Moore et al. 2013). With these approaches, much attention has been paid to analyses of the stress magnitude and orientation in the Nankai accretionary prism in order to understand the processes of interseismic stress accumulation (e.g., Kinoshita and Tobin, 2013) caused by plate convergence that result in the Nankai megaearthquakes. These analyses involve borehole breakout and drilling-induced 
tensile fractures (Lin et al. 2010), stress inversion from micro-fault sets with striations (Lewis et al. 2013), the anelastic strain recovery (ASR) method (Byrne et al. 2009; Yamamoto et al. 2013), and various geophysical models (e.g., Wu et al. 2013).

In this paper, we present the analyses of the microstructures in calcite veins that occur in two cutting samples of mudstones retrieved by riser drilling through Hole C0002F during the IODP Expedition 338 in 2012. We clearly document the reversal of the stress field based on analyses of microstructures in one of the calcite vein samples, and then, we discuss the origin of such stress reversal in the Nankai accretionary prism.

\section{Geological setting and sample description}

During the IODP Expedition 338, Hole C0002F was drilled from 856 meters below the seafloor (mbsf) down to 2,005.5 mbsf by riser drilling, and cuttings were retrieved at every $5 \mathrm{~m}$. The Site C0002 is located at the inner wedge of the Nankai Miocene accretionary prism, which is covered by the Kumano Basin forearc deposit (see Figure 1). Geophysical logging was conducted continuously for this drilling interval, and from this, three lithological units termed III, IV, and V have been identified (Moore et al. 2013). Three units were also confirmed by direct lithological observations of cuttings retrieved by the riser drilling, and from these data, units IV and V were further divided into five and two subunits depending on the content of sandstones.

Unit III (875.5 to $918.5 \mathrm{mbsf}$ ) is mainly composed of clay- to silt-rich sediments, with occasional thin, interbedded sand layers. Logging unit III identified in Hole C0002F correlates with Hole C0002A unit III defined during Expedition 314 (Expedition 314 Scientists, 2009), and also unit III in Hole C0002B, which was interpreted as basal Kumano Basin forearc sediment (Expedition 315 Scientists, 2009). While unit IV (918.5 to $1,638 \mathrm{mbsf}$ ) is composed of the alternations of thick sand-rich and mudrich sediments with the variable sand ratios, unit V $(1,638$ to 2,005.5 mbsf) consists of homogeneous mud-rich sediments. Both units IV and V constitute the inner wedge of the Nankai Miocene accretionary prism.

For deformation structures, vein structures (Figure F10C of Moore et al. 2013), which are similar to deformation bands (Figure F10D of Moore et al. 2013) and not mineral veins such as the carbonate veins described in this study, were observed in cores and cuttings exclusively from unit III in Holes C0002F and C0002J. For units IV and $\mathrm{V}$ of the accretion prism, cuttings with slickenlined surface and carbonate veins occur, and these indicate the styles of deformation in the accretion prism (Moore et al. 2013). Frequency distributions versus the depths of cuttings with these deformation structures are summarized in Figure 1c.
For mudstone cuttings with carbonate veins, which we described on board during the IODP Expedition 338, it was later discovered that almost all of the carbonate veins are felsic tuffs, which consist of glass shards and a very fine-grained matrix. While the very fine-grained matrix, which could have been also originally very fine-grained glass, has now been completely altered to calcite, the coarse-grained glass shards have only been partly altered to calcite. Occurrences of felsic tuffs, the composition of glass shards, and deformation microstructures in felsic tuffs will be reported elsewhere. Since calcite veins occur in the felsic tuffs as mentioned below, calcium carbonate was perhaps dissolved into pore fluids in the rocks and then precipitated in extension fractures forming calcite veins. We found only two calcite vein samples among all the cuttings during the expedition; the samples, $\mathrm{CV}-1$ and CV-2, were collected from cutting samples of 56-SMW (drill bit depth, 1,085.5 mbsf) and 258-SMW (1,885.5 mbsf), respectively (Figure 1).

\section{Methods}

First, thin sections were made from the two calcite vein samples so that the vein wall was nearly perpendicular to the plane of the thin section. For CV-1, since it is difficult to see the 3-D orientation of the boundary between calcite veins and wall rocks consisting of felsic tuffs (Figure 2a), the thin section was made so that the vein walls were approximately perpendicular to the plane of the thin section. For CV-2, which was probably peeled off from the wall rocks and occurs without them, the vein wall was exactly perpendicular to the plane of the thin section (Figure 2d). The thin sections were further polished with colloidal silica to remove damage on the surface, which is necessary for the measurement of crystallographic orientations with the electron back-scattered diffraction (EBSD) method (e.g., Randle, 2003). The EBSD measurements were conducted using a scanning electron microscope (SEM; Hitachi SU-3500, Hitachi High Technologies, Minato-ku, Tokyo, Japan) equipped with an EBSD detector (HKLNordlys detector, Oxford Instruments, Abingdon, UK) that was installed at the National Institute of Advanced Industrial Science and Technology (AIST). Also, the paleostress analysis using mechanical $e$-twins in calcite was conducted for grains with $e$-twins for both samples CV-1 and CV-2 following the method (Figure 3a) of Turner and Weiss (1963). Here, both orientations of $c$-axis and pole to $e$-twin were measured with a U-stage mounted on a Nikon petrographic microscope (Nikon Instruments, Chiyoda-ku, Tokyo, Japan). This method utilizes the fact that the mechanical $e$-twin is only formed by a unique sense of shear on the plane of the $e$-twin resulting in the $52.5^{\circ}$ rotation of the $c$-axis in a twinned part, and not by the opposite sense of shear, which is caused by the extension in the host $c$-axis orientation (Figure $3 \mathrm{a})$ ). The compression $\left(\sigma_{1}\right)$ 


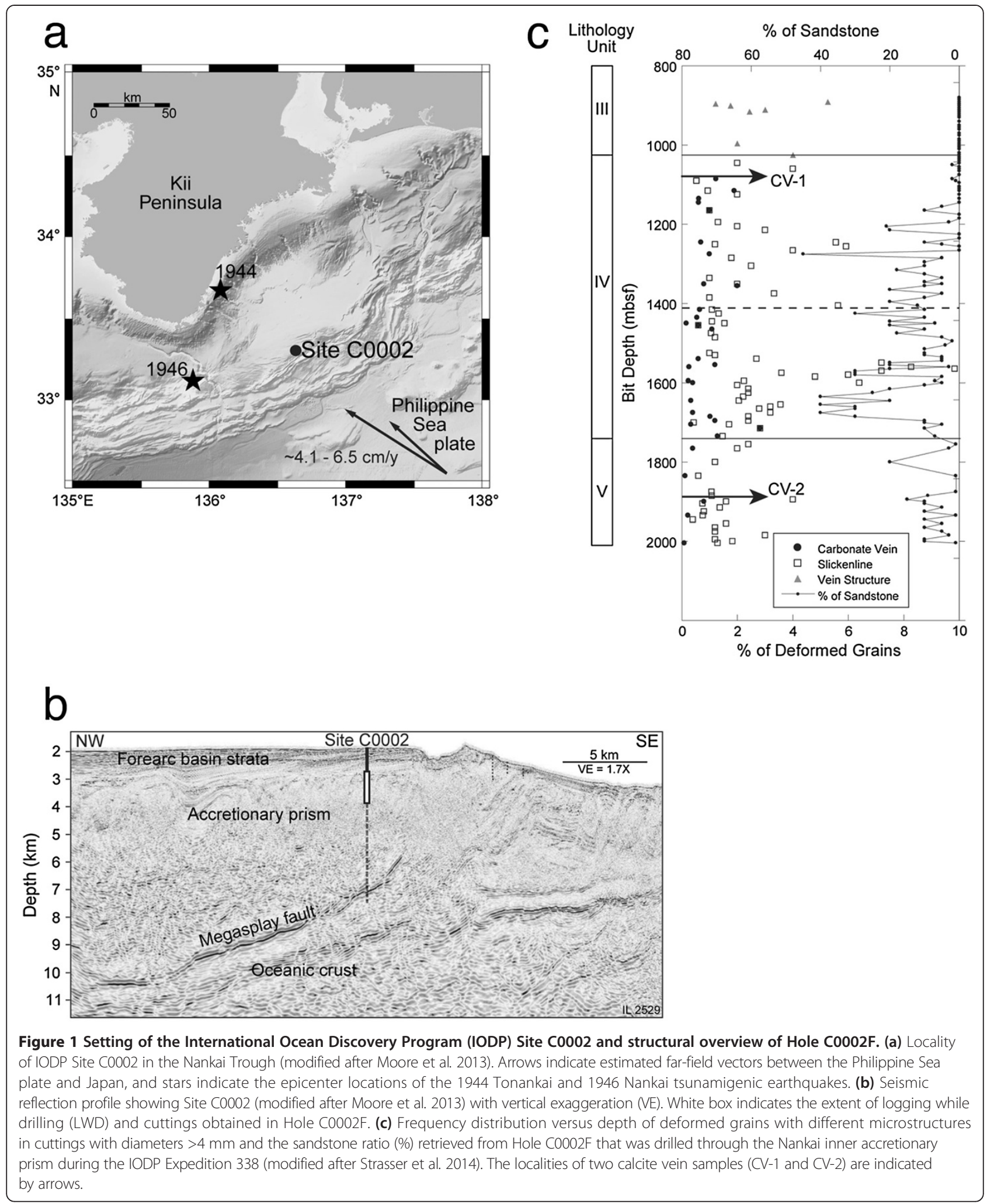

and extension $\left(\sigma_{3}\right)$ axes are thus determined by assuming that the $e$-twin plane is most favorably oriented for activation relative to the stress directions. In the measurements, since it is known from crystallography that the orientations of the host $c$-axis and pole to the $e$-twin make a fixed angle of $26.25^{\circ}$, the measured angles less than $21^{\circ}$ and 

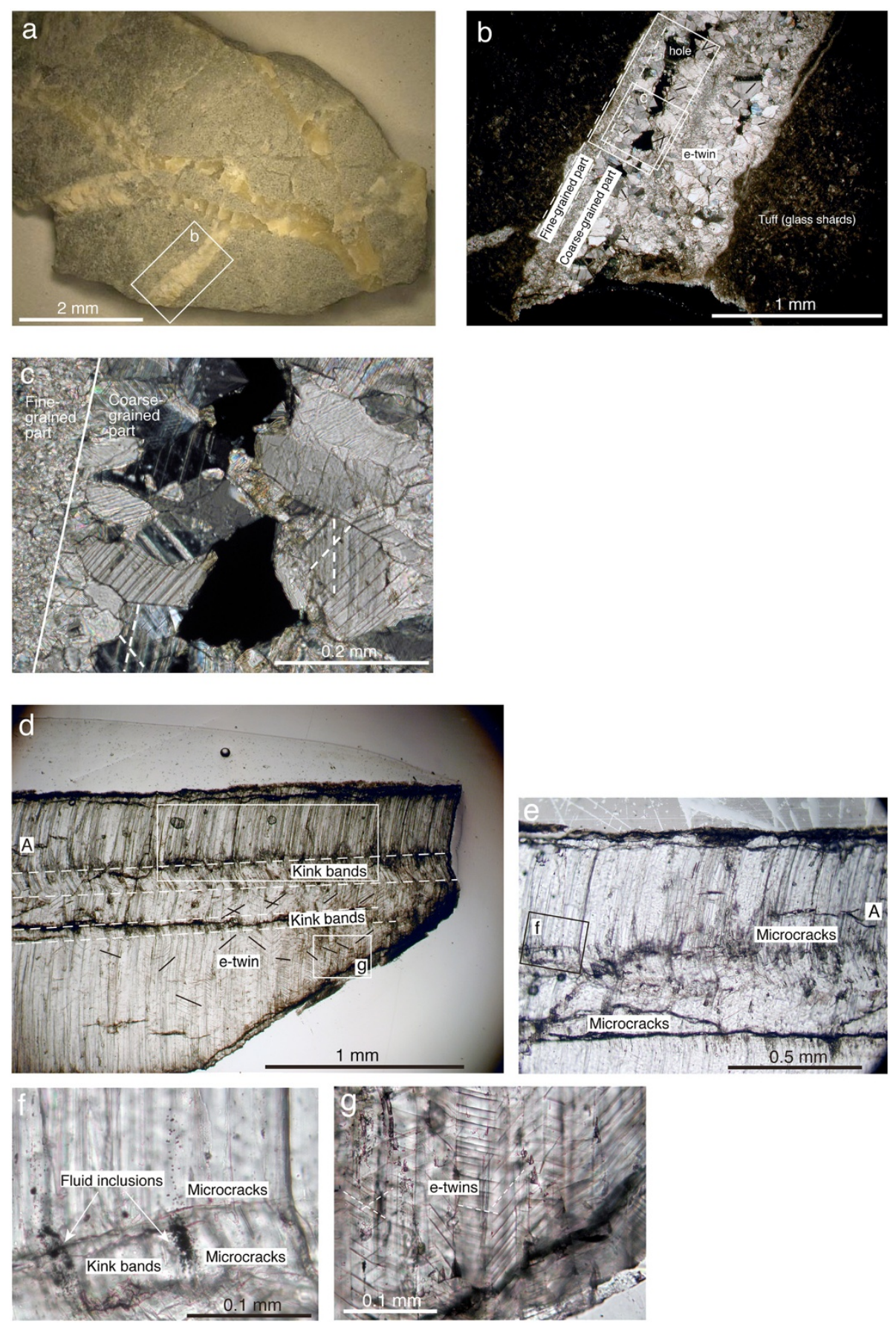

Figure 2 Calcite veins in cuttings (CV-1, sample 338-C0002F-56-SMW; CV-2, sample 338-C0002F-258-SMW). (a) Calcite veins in cuttings (CV-1, sample 338-C0002F-56-SMW, after Figure F10. E. of Moore et al. 2013). (b-g) Photomicrographs of analyzed calcite vein samples. (b) CV-1 (crossed polarized light). Note that the abrupt change in grain size between the fine-grained and coarse-grained parts. (c) $e$-twins in calcite grains from CV-1 (crossed polarized light). The locality is shown in (b) by a frame. (d) Calcite vein in cuttings (CV-2, sample 338-C0002F-258-SMW, plane polarized light). Mechanical e-twins are indicated by solid bars, and two sets of e-twins are sometimes developed (shown by crosses). (e) Another part of calcite vein sample CV-2 (plane polarized light), where ' $A$ ' denotes the same point as ' $A$ ' in (d). (f) Concentration of fluid inclusions in kink bands from CV-2 (plane polarized light). The locality is shown in (e) by a frame. (g) Development of e-twins in fibrous calcite grains from CV-2 (shown by dashed lines, plane polarized light). The locality is shown in (d) by a frame. The frames shown by solid lines in (b) and (d) indicate the locality of crystallographic orientation measurements with electron back-scattered diffraction (EBSD) (Figures 4 and 5). See text for explanations. 


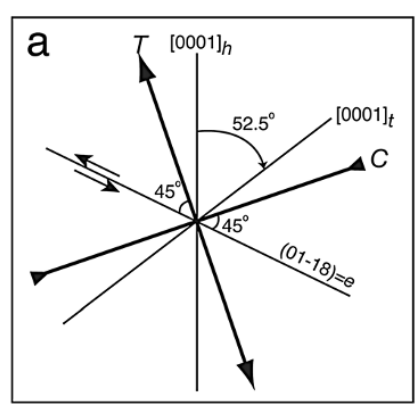

b

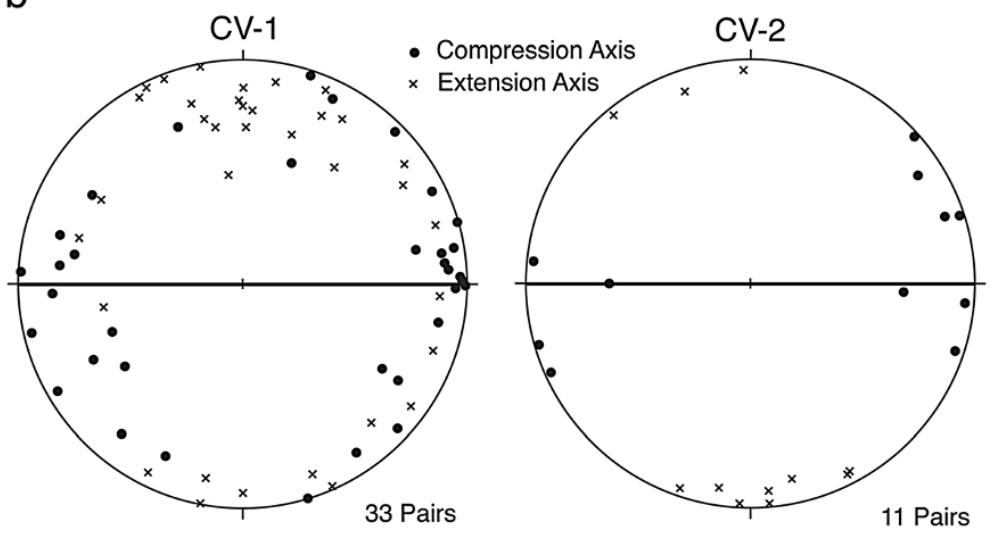

Figure 3 Paleostress analysis with mechanical e-twin in calcite. (a) Principle after Turner and Weiss (1963). [0001] $]_{h}$ and [0001] $]_{t}$ indicate the $c$-axis orientations of host and twinned parts, respectively. See text for explanations. (b) Results of paleostress analyses with mechanical e-twin for calcite vein samples CV-1 (338-C0002F-56-SMW) and CV-2 (338-C0002F-258-SMW). The numbers of analyzed pairs of c-axis and e-twin orientations are shown at the lower-right corner of each diagram. Thick straight lines indicate the orientation of the vein wall. See text for explanations.

greater than $31^{\circ}$ were rejected after considering an error of $5^{\circ}$ for the measurements with a U-stage.

\section{Results}

For CV-1, the shape of calcite grains is blocky, and it is clear that the grain size varies in the direction perpendicular to the vein wall (Figure $2 \mathrm{~b}, \mathrm{c}$ ). In direct proximity to the vein wall, the size of grains is as fine as 10 to 30 $\mu \mathrm{m}$, while in the central part apart from the vein wall, the grain size is as coarse as 50 to $100 \mu \mathrm{m}$. Since the change of grain size is abrupt, we separately measured the crystallographic orientations for the fine-grained (Figure $4 \mathrm{a}$ ) and coarse-grained parts (Figure 4b). For the fine-grained part, we utilized the automatic measurements of crystallographic orientations of calcite grains within a certain area with EBSD. As shown in Figure 4a, a weak preferred orientation of the $c$-axis, which is rotated counterclockwise by $c .30^{\circ}$ about the vertical axis relative to the vein normal orientation, and a girdle distribution of the $a$-axis perpendicular to the $c$-axis maximum orientation were developed in the fine-grained part. For the coarse-grained part, we measured the crystallographic orientations of individual calcite grains with EBSD (Figure 4b). As shown in Figure 4b, the $c$-axes of coarse calcite grains are weakly preferentially oriented perpendicular to the vein wall, while the $a$-axis orientations constitute a girdle perpendicular to the maximum orientation of the $c$-axis. Here, an uneven distribution of the $c$-axis maximum relative to the horizontal plane can perhaps be attributed to the slight tilt of the vein wall from the orthogonal orientation to the thin section.

For $\mathrm{CV}-2$, the shape of calcite grains is fibrous with a constant width of $c .20 \mu \mathrm{m}$, the long axis of which is perpendicular to the vein wall (Figure 2d). Also, kink bands are developed, where the kink band boundaries are parallel to the vein wall, and fractures are developed nearly along the axial plane of kink folds (Figure 2d,e,f). Further, in some parts of the kinked bands elongated parallel to the fibers long axis, fluid inclusions are densely distributed (Figure 2f). For CV-2, the crystallographic orientations of 100 individual grains for unkinked and kinked parts were measured (Figures $2 \mathrm{~d}$ and 5). First, the $c$-axis orientations for the unkinked part are very strongly preferentially oriented perpendicular to the vein wall, while the $a$-axis orientations constitute a girdle perpendicular to the $c$-axis maximum, and hence, they are more or less parallel to the vein wall (Figure 5a). For the kinked part, this pattern of crystallographic orientations is just rotated counterclockwise by c. $10^{\circ}$ (Figure 5b), which is almost in accord with the rotation angle of the 


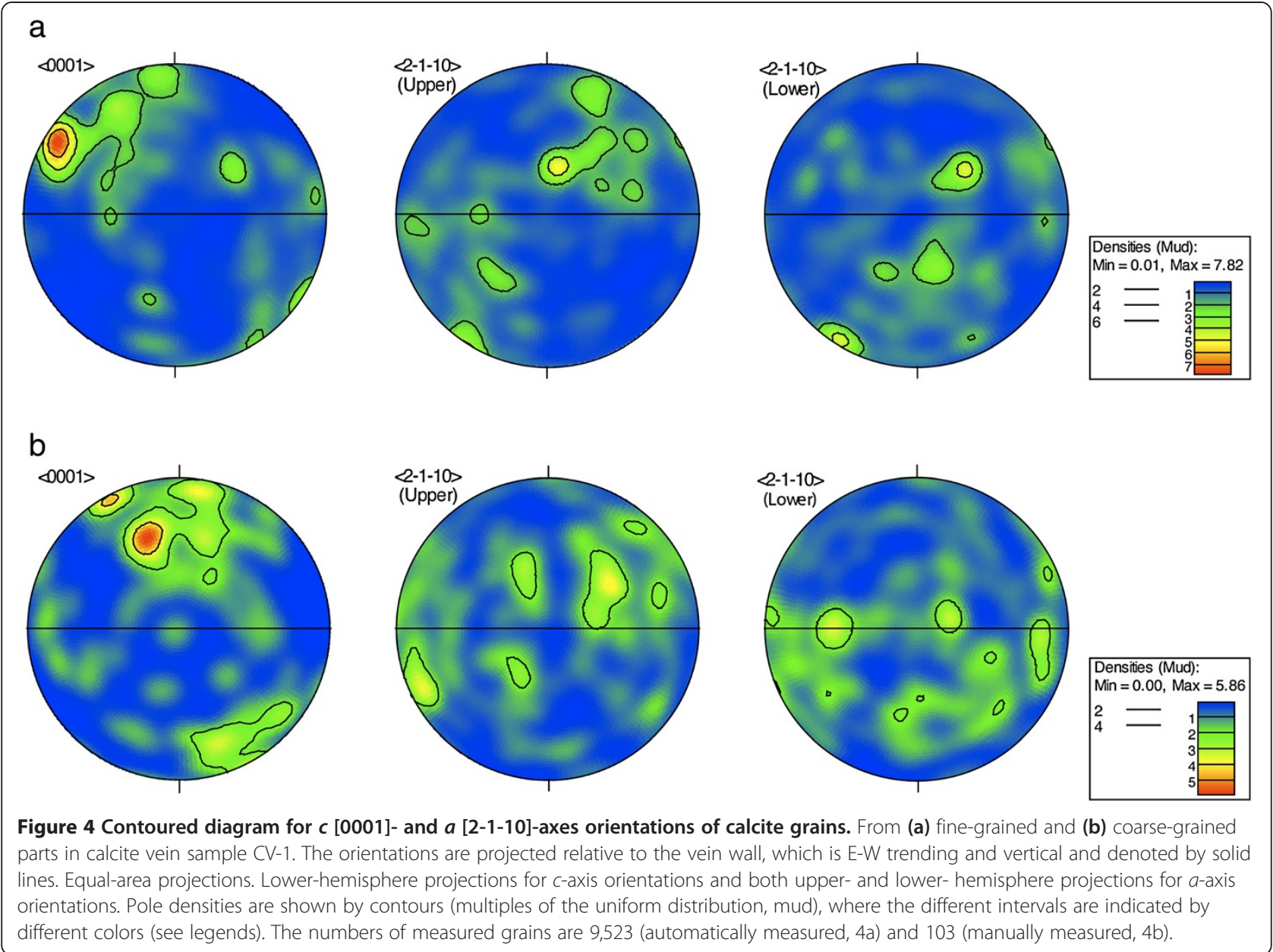

long axis of fibrous grains (Figure 2d,e,f). Furthermore, the orientations of mechanical $e$-twins mentioned below are rotated more than $10^{\circ}$ about the axis of kink bands.

The results of the paleostress analysis with mechanical $e$-twins will be described below. While the occurrence of $e$-twins with a certain width in calcite grains is obvious in sample CV-1 (Figure 2c), their occurrence is not so clear in sample $\mathrm{CV}-2$ under a petrographic microscope at low magnifications (Figure 2d). However, the very fine hair-like microstructures, which are oblique to the vein wall at low angles, can be clearly observed at high magnifications in sample CV-2 (Figure 2g). While these linear structures usually occur as a set of parallel lines in each of the fibrous grains, two sets of parallel lines in the different directions are sometimes developed in single grains in sample CV-2 (Figure 2d,g). Similarly, two sets of $e$-twins are sometimes developed in single grains in sample CV-1 (Figure 2c). These structural elements are in fact mechanical $e$-twins, which have been verified by the fact that the measured host $c$-axis and pole to $e$ twin orientations make an angle close to the fixed orientation of $26.25^{\circ}$. Here, mechanical $e$-twins were even formed at shear stresses as low as $10 \mathrm{MPa}$ at room temperatures, and no other slip systems such as $r$-slip systems that can be activated at conditions higher than 100 MPa (Turner et al. 1954) were in operation, as evidenced by the absence of wavy extinction. Hence, the magnitude of shear stresses, which is inferred to have varied between 10 to $100 \mathrm{MPa}$, cannot be constrained to a narrow range in the present calcite veins. Alternatively, Rybacki et al. (2011) proposed a paleopiezometer as a function of $e$-twin density in calcite based on deformation experiments. According to their results, the measured twin densities of $c .100 / \mathrm{mm}$ and $c .140 / \mathrm{mm}$ in calcite grains from samples $\mathrm{CV}-1$ and $\mathrm{CV}-2$ are converted to very high differential stresses of c. $200 \mathrm{MPa}$ and c. $230 \mathrm{MPa}$, respectively.

For sample CV-1, the inferred extension directions from the $e$-twin method are mostly oriented perpendicular to the vein wall, the preferred orientation of which is similar to that of the $c$-axis orientations, while the compression directions are parallel to the vein wall, although they are fairly scattered (Figure $3 \mathrm{~b}$ ). For sample CV-2, the extension and compression axes are oriented very 


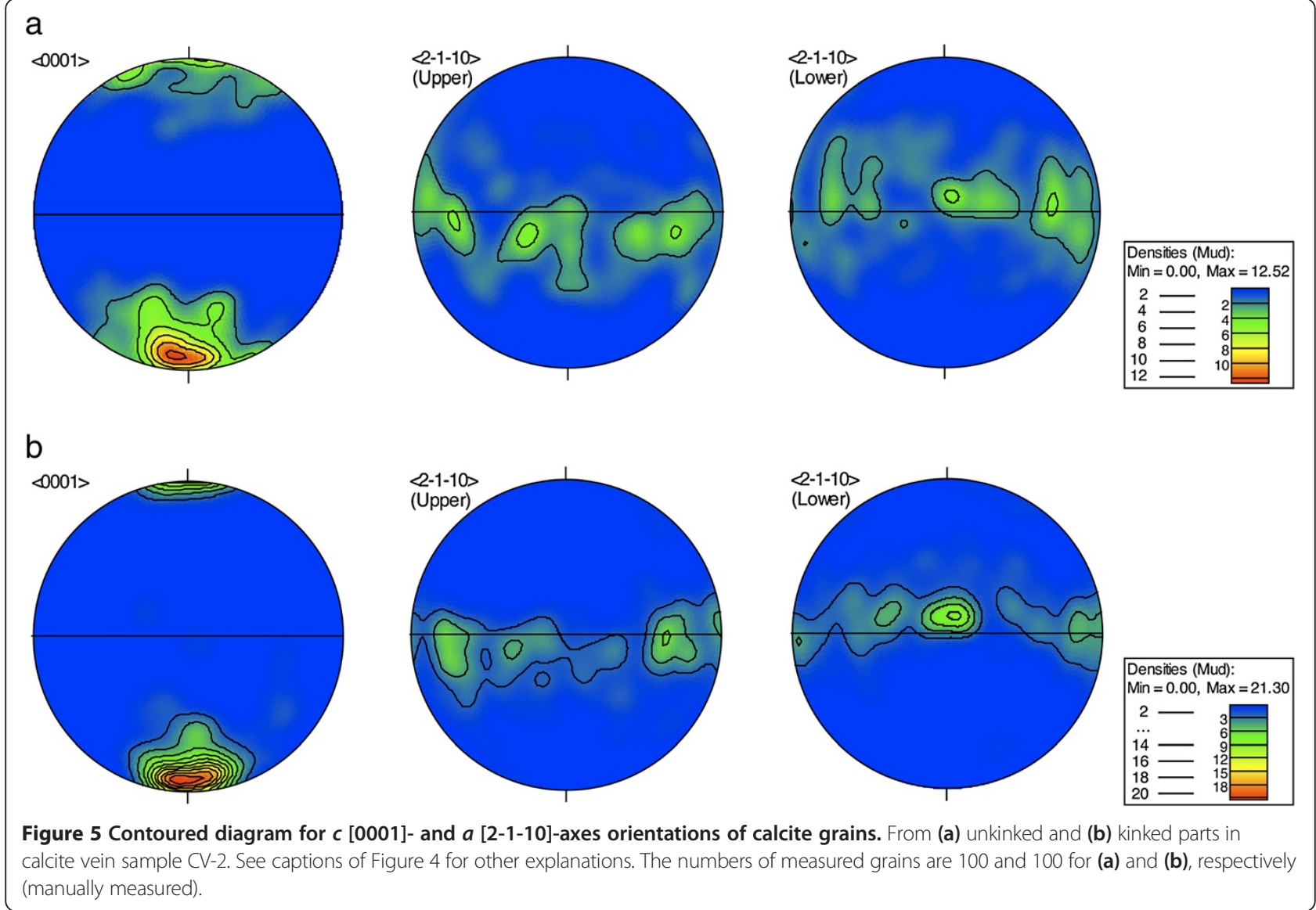

similar to those in sample CV-1 and are much more concentrated, although the number of data points is scarce (Figure 3b). These orientations of principal stresses can also be easily inferred because of the bisectors of obtuse and acute angles of the crossing of two $e$-twins in single grains (Figure 2c,g), which are the directions of the extension and compression axes that are oriented in those directions mentioned above, respectively.

\section{Discussion}

The preferred orientation of the $c$-axis perpendicular to the vein wall in both samples is probably caused by anisotropic growth (i.e., dependence of the growth rate on crystallographic orientation) of calcite grains from the solution. It is known that for quartz veins, the similar preferred orientation was developed as the constituting quartz aggregates precipitated from the solution (e.g., Takeshita and Hara, 1998; Nishikawa and Takeshita, 1999). The wall rocks consisting of calcite produced by the alterations of felsic tuff were dissolved into the fluid, which percolated along the extension fractures created parallel to the vein wall. The calcite crystals for both vein samples started to grow from the surface of the vein wall by using the crystals along it as seed crystals (i.e., syntaxial growth) as the extension fractures opened. Here, the growth of calcite crystals mainly occurred in the direction of the vein opening, and those calcite grains with a $c$-axis parallel to the opening direction grew faster than those with other orientations (i.e., competitive growth, Passchier and Trouw, 2005; Bons et al. 2012). As a result, the grains favorably oriented for growth became dominant as the veins widened, which led to the $c$-axis preferred orientation parallel to the vein opening direction (Figures 4 and 5). In fact, the grain size of calcite in sample CV-1 increased toward the center of the vein because the grains favorably oriented for growth grew faster via competitive growth during the vein opening. This interpretation is evidenced by the difference in preferred $c$-axis orientations between the fine- and coarse-grained parts, where the preferred $c$-axis orientation in the latter part is more closely oriented in the vein normal orientation than in the former part (Figures 2 and 4). We do not know the origin of the preferred $c$-axis orientation in the fine-grained part, which may have been inherited from that in calcite aggregates constituting the matrix of wall rocks. However, the difference in grain shapes in the veins, such as blocky versus fibrous shapes, has been interpreted in the following way. Following Urai et al. (1991) and Oliver and Bons (2001), it 
is interpreted that veins consisting of fibrous grains were formed when the vein opening was by small increments, while blocky ones were formed when the rate of wall rock displacement surpasses that of crystal growth.

For sample CV-2, it has been shown that two microstructures, kink bands and mechanical $e$-twins, are developed in calcite grains. The kink bands were developed by the compression parallel to the long axis of fibrous calcite grains (i.e., buckling, Ramsay, 1967), and hence, it is perpendicular to the vein wall. The fact that fluid inclusions are concentrated in some parts of the kinked bands elongated parallel to the fiber long axis suggests that dilation occurred normal to the fiber long axis, thereby providing evidence that these microstructures that are correlated with dilation veins in a kink band (Ramsay, 1967) are in fact caused by kinking. Further, brittle fractures were formed along the axial plane of kink folds (Figure 2d), which indicates that the formation of kink bands (or folds) was accommodated by brittle fractures under very low temperatures. Therefore, the possibility that the apparently curved fiber veins were formed by a change in the opening direction of the veins (e.g., Passchier and Trouw, 2005; Bons et al. 2012) can be completely rejected.

Conversely, the mechanical $e$-twins with the pole orientation that makes small angles to the fibers long axis in the calcite grains, which is nearly parallel to the $c$-axis, were formed in $\mathrm{CV}-2$, which indicates extension parallel to the fibers long axis. Therefore, it can be inferred that the fibrous grains in CV-2 were first formed by vein opening followed by precipitation of fibrous calcite grains, which was further followed by the formation of $e$-twins under extension perpendicular to the vein wall. Subsequently, the veins were compressed in the direction perpendicular to the vein wall, and kink bands and brittle fractures were formed along the axial plane of the kink folds, which indicates that the stress direction perpendicular the vein wall was reversed. In fact, the orientations of mechanical $e$-twins are rotated more than $10^{\circ}$ about the axis of kink bands, thus showing the validity of the inferred order of microstructural development.

There may be many possible interpretations for the stress reversal because the kinematic framework where the stress reversal occurred cannot be constrained in the unoriented cutting sample. It has been shown that the sedimentary strata constituting the Nankai Upper Miocene accretionary prism drilled by the IODP Expedition 338 are strongly folded based on the seismic reflection and logging data (Figures F3 and F7 of Moore et al. 2013). First, the present stress reversal can be interpreted as being related to the development of folds. For example, we can assume that the calcite vein is formed horizontally by fluid overpressure during the layer-parallel shortening of horizontal strata preceding the formation of folds (Figure 6a), which results from the trench normal

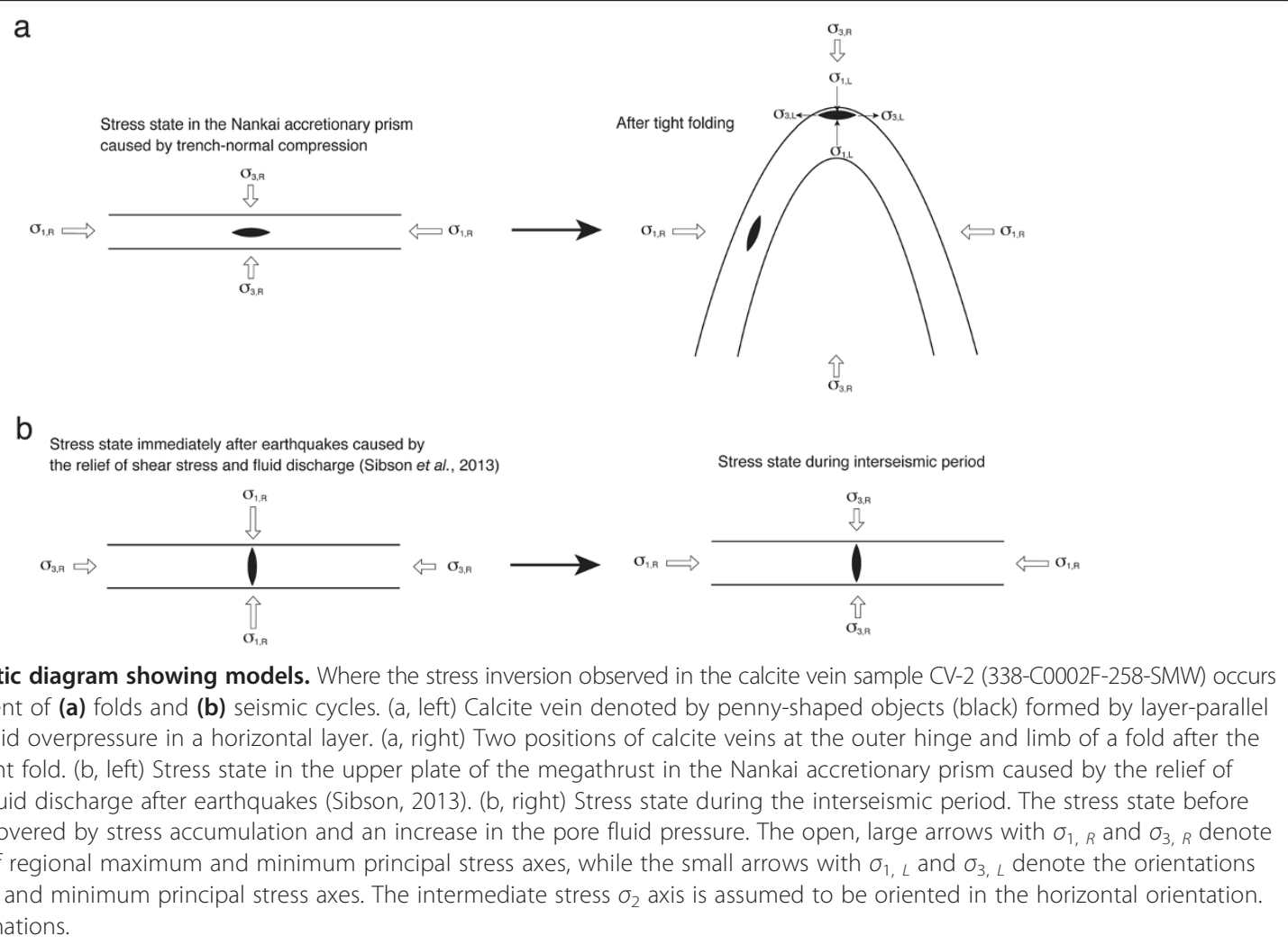


compression inferred at most parts of the Nankai accretionary prism (e.g., Wu et al. 2013). As the fold develops, it is possible that the position where the calcite vein is formed moves to the outer arc of the core of the fold, where the layer parallel extension, and hence the vertical shortening, can occur (Figure 6a, e.g., Dietrich and Carter, 1969); this can explain the stress reversal. Alternatively, if the orientation of calcite veins is rotated by up to $90^{\circ}$ in a limb of the fold during the formation of tight folds, the vein normal extension is followed by vein normal compression, which can explain the stress reversal (Figure 6b).

Other possible explanations for the stress reversal are related to seismic cycles. The $M_{w}$ 9.0 Tohoku-Oki earthquake occurred off the Pacific coast of northeast Japan on March 11, 2011. Since this megaearthquake, some unexpected inland earthquakes have occurred along the Pacific coast of northeast Japan, which are mostly of the normalfaulting type including the April 11, $2011 \mathrm{M}_{\mathrm{w}} 6.6$ Iwaki earthquake (e.g., Kato et al. 2011; Okada et al. 2011; Fukushima et al. 2013). These earthquakes are unusual because the hypocenters had been under a weak E-W compression before the megaearthquake, which changed to an E-W extension after it. These unusual earthquakes were interpreted to have been caused by the stress changes resulting from the release of elastic strain energy at places where the differential stresses were very low at an order of $1 \mathrm{MPa}$ (Hasegawa et al. 2011; Yoshida et al. 2012). Therefore, it is possible that the repetition of compression and extension during the seismic cycles also occurred in the past along major subduction zones in the world, including the Nankai one, if the differential stresses were as low as that in the Tohoku forearc region before the earthquakes.

Alternatively, Sibson (2013) interpreted this stress reversal associated with the Tohoku-Oki earthquake by the fault valve model (Sibson, 1992), where the pore fluid pressure is built up before the earthquake, and this lowers the effective normal stress and results in seismic rupture on the fault plane. According to his model, although the stress field in the forearc hanging wall above the megathrust was in an E-W horizontal compression state and a vertical extension before the Tohoku-Oki earthquake, that was switched to an E-W horizontal extension and vertical compression immediately after the earthquake due to the release of horizontal stress and fluid discharge leading to a decrease in the pore fluid pressure. Fluids, which were discharged from the megathrust, are inferred to have percolated along the vertical cracks under the horizontal, extensional stress in the hanging wall. In fact, such vertical, extensional fault-fracture systems of different scales were reported from ancient accretionary prisms where fluid percolation along the fractures was exemplified by the formation of mineral veins precipitated from the solution. Sibson (2013) argued that different scales of extensional fault-fracture systems exist, which depend on the degree of release of seismic energy, and for example, one can refer to the large-scale Alsaska-Juneau Au deposit hosted by quartz veins (Goldfarb et al. 1988; Miller et al. 1994) and the small-scale quartz-carbonate veins in the Nobeoka thrust zone in the Shimanto accretionary complex in Kyushu, Japan (Yamaguchi et al. 2011). The forearc horizontal extension immediately after the earthquakes is again succeeded by horizontal compression when the fractures along the megathrust are sealed by mineral veins and the strength is recovered. Therefore, the stress reversal in the present calcite vein sample can be also interpreted in this way. However, if the present calcite vein is originally formed in the horizontal direction associated with the buildup of pore fluid pressure along the megthrust, the stress reversal is caused immediately after the earthquake when the vertical stress is switched from $\sigma_{3}$ to $\sigma_{1}$. Although we cannot determine which model is most likely for the present case, it is worthwhile mentioning that such a stress reversal has been found for the first time at depths reaching up to 2,000 mbsf in the presently forming accretionary prism, and the exact cause for this might be deciphered if the oriented core samples with a known kinematic framework are analyzed in the future.

\section{Conclusions}

Deformation microstructures and preferred orientations of calcite grains in two calcite vein samples from Hole C0002F drilled at depths of 1,085.5 and 1,885.5 mbsf during the IODP Expedition 338 in 2012 were analyzed. For both samples, the $c$-axes of calcite grains are preferentially oriented perpendicular to the vein wall, which is indicative of competitive growth of calcite during the vein opening caused by vein normal extension. Additionally, mechanical $e$-twins are developed in both samples, which are inferred to have been developed under the same stress field as that responsible for the formation of calcite veins based on the paleostress analyses in grains with $e$-twins. For the calcite vein retrieved at the depth of 1,885.5 mbsf, kink bands that developed by compression in the direction perpendicular to the vein wall are also present, which is indicative of stress reversal after the formation of mechanical $e$-twins. Although we could not definitely reach a conclusion about the cause of the stress reversal at the present time, it could have occurred during either the development of folds or seismic cycles in the Nankai accretionary prism, and this can be analyzed using the oriented core samples in the future.

Competing interests

The authors declare that they have no competing interests.

\section{Authors' contributions}

$\pi$ carried out the paleostress analyses with e-twins in calcite from calcite vein samples and drafted the manuscript. AY collected the calcite vein samples used for the present study during IODP Expedition 338 in 2012 and discussed about the scientific content of the manuscript with TT. NS carried 
out the measurements of preferred orientations of calcite from calcite vein samples with EBSD installed at the AIST. All authors read and approved the final manuscript.

\section{Acknowledgements}

We thank Dr. W. Lin and an anonymous reviewer for their constructive review of the manuscript. This research used samples and data provided by the Integrated Ocean Drilling Program, now called the International Ocean Discovery Program (IODP). The authors thank Drs. M. Strasser, B. Dugan, K. Kanagawa, G. F. Moore, S. Toczko, L. Maeda, the IODP Expedition 338 scientists, the onboard laboratory technicians (Marine Works Japan), and the operation staff of DN Chikyu for their assistance during our research.

\section{Author details}

'Department of Natural History Sciences, Graduate School of Sciences, Hokkaido University, Sapporo 060-0810, Japan. ${ }^{2}$ Atmosphere and Ocean Research Institute, The University of Tokyo, Chiba 277-8564, Japan. ${ }^{3}$ Geological Survey of Japan, National Institute of Advanced Industrial Science and Technology, AIST Tsukuba Central 7, 1-1 Higashi, Tsukuba, Ibaraki 305-8567, Japan.

Received: 7 March 2014 Accepted: 14 October 2014

\section{Published online: 29 October 2014}

\section{References}

Ando M (1975) Source mechanisms and tectonic significance of historical earthquakes along the Nankai Trough, Japan. Tectonophysics 27:119-140

Bons PD, Elburg MA, Gomez-Rivas E (2012) A review of the formation of tectonic veins and their microstructures. J Struct Geol 43:33-62

Byrne TB, Lin W, Tsutsumi A, Yamamoto Y, Lewis JC, Kanagawa K, Kitamura Y, Yamaguchi A, Kimura G (2009) Anelastic strain recovery reveals extension across SW Japan. Geophys Res Lett 36, L23310, doi:10.1029/2009GL040749

Chamot-Rooke N, Renard V, LePichon X (1987) Magnetic anomalies in the Shikoku Basin: a new interpretation. Earth Planet Sci Lett 83:214-228

Dietrich JH, Carter NL (1969) Stress-history of folding. Am J Sci 267:129-154

Expedition 314 Scientists (2009) Expedition 314 Site C0002. In: Kinoshita M, Tobin H, Ashi J, Kimura G, Lallemant S, Screaton EJ, Curewitz D, Masago H, Moe KT, the Expedition 314/315/316 Scientists (eds) Proc. IODP, 314/315/316. Integrated Ocean Drilling Program Management International, Inc, Washington, DC, doi:10.2204/iodp.proc.314315316.114.2009

Expedition 315 Scientists (2009) Expedition 315 Site C0002. In: Kinoshita M, Tobin H Ashi J, Kimura G, Lallemant S, Screaton EJ, Curewitz D, Masago H, Moe KT, the Expedition 314/315/316 Scientists (eds) Proc. IODP, 314/315/316. Integrated Ocean Drilling Program Management International, Inc, Washington, DC, doi:10.2204/iodp.proc.314315316.124.2009

Fukushima Y, Takada Y, Hashimoto H (2013) Complex ruptures of the 11 April 2011 Mw6.6 Iwaki earthquake triggered by the 11 March 2011 Mw9.0 Tohoku earthquake, Japan. Bull Seismol Soc Am 103:1572-1583

Goldfarb RJ, Leach DL, Pickthorn WJ, Paterson CJ (1988) Origin of lode-gold deposits of the Juneau gold belt, southeastern Alaska. Geology 16:440-443

Hasegawa A, Yoshida K, Okada T (2011) Nearly complete stress drop in the $2011 \mathrm{Mw}_{\mathrm{w}}$ 9.0 off the Pacific coast of Tohoku Earthquake. Earth Planets Space 63:703-707

Kato A, Sakai S, Obara K (2011) A normal-faulting seismic sequence triggered by the 2011 off the Pacific coast of Tohoku Earthquake: wholesale stress regime changes in the upper plate. Earth Planets Space 63:745-748

Kinoshita M, Tobin H (2013) Interseismic stress accumulation at the locked zone of Nankai Trough seismogenic fault off Kii Peninsula. Tectonophysics 600:153-164

Lewis J, Byrne T, Kanagawa K (2013) Evidence for mechanical decoupling of the upper plate at the Nankai subduction zone: constraints from core-scale faults at NantroSElZE Sites C0001 and C0002. Geochem Geophys Geosyst 14:620-633, doi:10.1029/2012GC004406

Lin W, Doan ML, Moore JC, McNeill L, Byrne TB, Ito T, Saffer D, Conin M, Kinoshita M, Sanada Y, Moe KT, Araki E, Tobin H, Boutt D, Kano Y, Hayman NW, Flemings P, Huftile GJ, Cukur D, Buret C, Schleicher AM, Efimenko N, Kawabata K, Buchs DM, Jiang S, Kameo K, Horiguchi K, Wiersberg T, Kopf A, Kitada K et al (2010) Presentday principal horizontal stress orientations in the Kumano forearc basin of the southwest Japan subduction zone determined from IODP NanTroSEIZE drilling Site C0009. Geophys Res Lett 37, L13303, doi:10.1029/2010GL043158

Miller LD, Goldfarb RJ, Gehrels GE, Snee LW (1994) Genetic links among fluid cycling, vein formation, regional deformation, and plutonism in the Juneau gold belt, southeastern Alaska. Geology 22:203-206
Miyazaki S, Heki K (2001) Crustal velocity field of southwest Japan: subduction and arc-arc collision. J Geophys Res 106:4305-4326, doi:10.1029/2000JB900312

Moore G, Kanagawa K, Strasser M, Dugan B, Maeda L, Toczko S et al (2013) NanTroSEIZE Stage 3: NanTroSEIZE plate boundary deep riser 2. IODP Prel Rept:338, doi:10.2204/iodp.pr.338.2013

Nishikawa O, Takeshita T (1999) Dynamic analysis and two types of kink bands in quartz veins deformed under subgreenschist conditions. Tectonophysics 301:21-34

Okada T, Yoshida K, Ueki S, Nakajima J, Uchida N, Matsuzawa T, Umino N, Hasegawa A, Group for the aftershock observations (2011) Shallow inland earthquakes in NE Japan possibly triggered by the 2011 off the Pacific coast of Tohoku Earthquake. Earth Planets Space 63:749-754

Oliver NHS, Bons PD (2001) Mechanisms of fluid flow and fluid-rock interaction in fossil metamorphic hydrothermal systems inferred from vein-wall rock patterns, geometry and microstructure. Geofluids 1:137-162

Park J-O, Kodaira S (2012) Seismic reflection and bathymetric evidences for the Nankai earthquake rupture across a stable segment-boundary. Earth Planets Space 64:299-303

Passchier CW, Trouw RAJ (2005) Microtectonics, 2nd edn. Springer, Berlin, p 366

Ramsay JG (1967) Folding and Fracturing of Rocks. McGraw-Hill, New York, p 568

Randle V (2003) Microtexture Determination and Its Applications, 2nd edn. Maney Publishing, London, p 138

Rybacki E, Janssen C, Wirth R, Chen K, Wenk H-R, Stromeyer D, Dresen G (2011) Low-temperature deformation in calcite veins of SAFOD core samples (San Andreas Fault) - microstructural analysis and implications for fault rheology. Tectonophysics 509:107-119

Seno T, Stein S, Gripp AE (1993) A model for the motion of the Philippine Sea plate consistent with NUVEL-1 and geological data. J Geophys Res 98:17941-17948, doi:10.1029/93JB00782

Sibson RH (1992) Implications of fault-valve behaviour for rupture nucleation and recurrence. Tectonophysics 211:283-293

Sibson RH (2013) Stress switching in subduction forearcs: implications for overpressure containment and strength cycling on megathrusts. Tectonophysics 600:142-152

Strasser M, Dugan B, Kanagawa K, Moore GF, Toczko S, Maeda L, Kido Y, Moe KT, Sanada Y, Esteban L, Fabbri O, Geersen J, Hammerschmidt S, Hayashi H, Heirman K, Hupers A, Jurado Rodriguez MJ, Kameo K, Kanamatsu T, Kitajima H, Masuda H, Milliken K, Mishra R, Motoyama I, Olcott K, Oohashi K, Pickering KT, Ramirez SG, Rashid H, Sawyer D et al (2014) Site C0002. In: Strasser M, Dugan B, Kanagawa K, Moore GF, Toczko S, Maeda L, the Expedition 338 Scientists (eds) Proc. IODP, 338. Integrated Ocean Drilling Program, Yokohama

Takeshita T, Hara I (1998) C-Axis fabrics and microstructures in a recrystallized quartz vein deformed under fluid-rich greenschist conditions. I Struct Geol 20:417-431

Tobin HJ, Kinoshita M (2006) NanTroSEIZE: the IODP Nankai Trough seismogenic zone experiment. Sci Drill 2:23-27

Turner FJ, Weiss LE (1963) Structural Analysis of Metamorphic Tectonites. McGraw-Hill, New York, p 545

Turner FJ, Griggs DT, Heard HC (1954) Experimental deformation of calcite crystals. Geol Soc Am Bull 65:883-934

Urai JL, Williams PF, van Roermund HLM (1991) Kinematics of crystal growth in syntectonic fibrous veins. J Struct Geol 13:823-836

Wu H-Y, Chan C-H, Kinoshita M, Saito S (2013) Stress field observation and modeling from the NanTroSEIZE scientific drillings in the Nankai Trough system, SW Japan. Tectonophysics 600:99-107

Yamaguchi A, Cox SF, Kimura G, Okamoto S (2011) Dynamic changes in fluid redox state associated with episodic fault rupture along a megasplay fault in a subduction zone. Earth Planet Sci Lett 302:369-377

Yamamoto Y, Lin W, Oda H, Byrne T, Yamamoto Y (2013) Stress states at the subduction input site, Nankai subduction zone, using anelastic strain recovery (ASR) data in the basement basalt and overlying sediments. Tectonophysics 600:91-98

Yoshida K, Hasegawa A, Okada T, Linuma T, Ito Y, Asano Y (2012) Stress before and after the 2011 great Tohoku-oki earthquake and induced earthquakes in inland areas of eastern Japan. Geophys Res Lett 39, L03302, doi:10.1029/ 2011GL049729, 2012.703-707

\section{doi:10.1186/s40623-014-0144-4}

Cite this article as: Takeshita et al: Stress reversal recorded in calcite vein cuttings from the Nankai accretionary prism, southwest Japan. Earth, Planets and Space 2014 66:144. 